\title{
Uniportal video-assisted thoracoscopic bronchial sleeve lobectomy: First report
}

\author{
Diego Gonzalez-Rivas, MD, FECTS, ${ }^{\mathrm{a}, \mathrm{b}}$ Ricardo Fernandez, MD, ${ }^{\mathrm{a}, \mathrm{b}}$ Eva Fieira, MD, ${ }^{\mathrm{a}}$ and \\ LuzDivina Rellan, MD, ${ }^{\mathrm{c}}$ Coruña, Spain
}

Thoracotomy is the traditional way to perform a bronchial sleeve lobectomy, but it also can be performed by videoassisted thoracic surgery (VATS). Most of the complex resections use 2 to 4 incisions, but the surgery can be done using only 1 incision. We report on uniportal VATS sleeve resection.

\section{CLINICAL SUMMARY}

A carcinoma in the right upper lobe with bronchial occlusion and distal pneumonitis (Figure 1, A) was diagnosed in a 55-year-old man. After the induction treatment (cisplatin-based therapy), VATS was the proposed approach for the patient (Figure 2,B). We placed the patient in a left lateral decubitus position. The patient had a VATS approach through a $5-\mathrm{cm}$ incision in the fifth intercostal space with no rib spreading (no soft tissue retractor and no direct

From the Department of Thoracic Surgery, ${ }^{a}$ Coruña University Hospital, Coruña, Spain; Minimally Invasive Thoracic Surgery Unit (UCTMI), ${ }^{\mathrm{b}}$ Coruña, Spain; and Department of Anaesthesia, ${ }^{c}$ Coruña University Hospital, Coruña, Spain. Disclosures: Authors have nothing to disclose with regard to commercial support. Received for publication Aug 15, 2012; revisions received Feb 1, 2013; accepted for publication Feb 13, 2013; available ahead of print March 18, 2013.

Address for reprints: Diego Gonzalez-Rivas, MD, FECTS, Department of Thoracic Surgery, Coruña University Hospital, Xubias 84, 15006 Coruña, Spain (E-mail: diego.gonzalez.rivas@sergas.es).

J Thorac Cardiovasc Surg 2013;145:1676-7 $0022-5223 / \$ 36.00$

Copyright $(c) 2013$ by The American Association for Thoracic Surgery http://dx.doi.org/10.1016/j.jtcvs.2013.02.052

visualization). A complete paratracheal and subcarinal lymph node dissection was initially undertaken. We placed the camera in the posterior portion of the incision, with instruments working below. We performed a right upper lobectomy, leaving the division of the bronchus as the last step of the procedure. We mobilized the interlobar artery to expose the bronchus and then divided the azygos vein. We made circumferential cuts to the mainstem bronchus and the intermediate bronchus with a knife on a long handle and scissors, removed the lobe, and divided the pulmonary ligament (Video 1).

We started the end-to-end anastomosis with a posterior stitch in the cartilaginous-membranous junction to help approximate the intermediate and mainstem bronchi and use it for continuous membranous suture (Video 2). We placed a row of 3/0 interrupted absorbable sutures at the posterior and medial portion of the bronchial cartilage with the help of an endoscopic knot-pusher. While placing the sutures, we tied the knots. We used continuous suture to close the membranous bronchus (from posterior to anterior). We then placed an interrupted suture in the anterior junction and tied it to the end of the running suture on the membranous wall.

We finished by using interrupted sutures for the anterior cartilaginous portion (Video 2). We did not use any tissue flap to protect the anastomosis. We placed a single chest tube through the incision (Figure 2, $A$ ). The postoperative bronchoscopy confirmed no stenosis (Figure 2, $B$ ).

The overall surgical time was 240 minutes. The patient was discharged from the hospital on the fifth postoperative day. The pathologic examination revealed a $1.7-\mathrm{cm}$ bronchial squamous cell carcinoma with no lymph node involvement (25 lymph nodes removed).
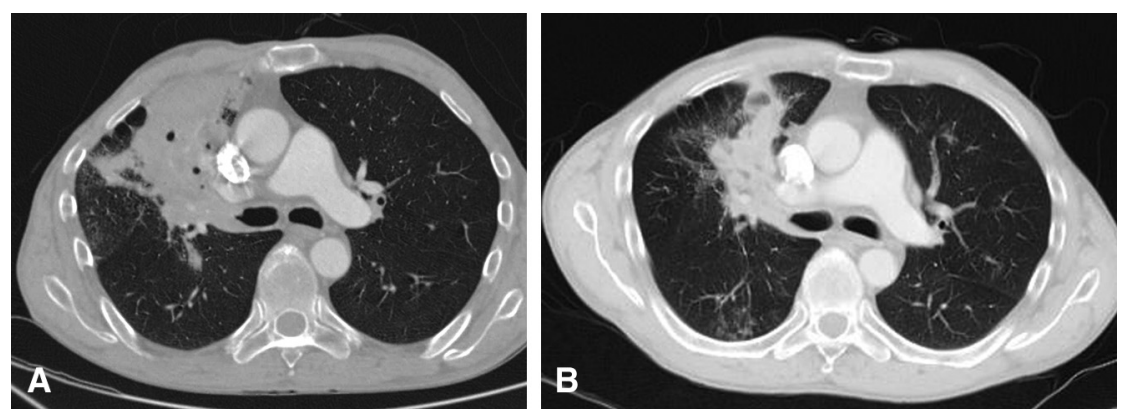

FIGURE 1. A, Computed tomography scan before chemotherapy. B, Computed tomography scan after induction chemotherapy. 

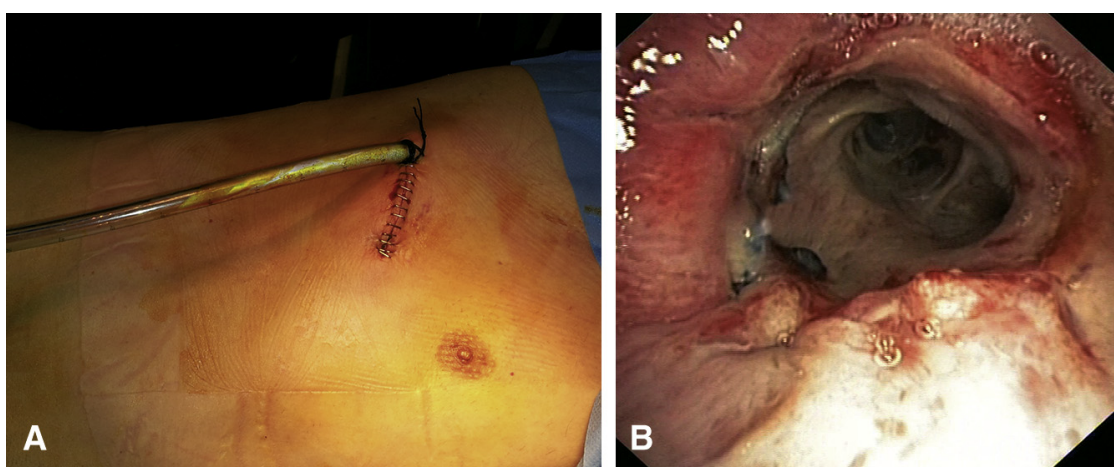

FIGURE 2. A, Postoperative result with chest tube placed in the posterior part of the incision. B, Postoperative bronchoscopy.

\section{DISCUSSION}

When feasible, sleeve resection is preferred to pneumonectomy to preserve pulmonary function in patients with centrally located lung tumors. VATS has been used for major lung resection since the early 1990s. The indications and contraindications of these procedures have changed over time. Until recently, the need for sleeve resection has been an absolute contraindication for VATS lobectomy. The long learning curve limits the number of surgeons who are able to master the sleeve technique by VATS. The first reports of VATS sleeve resection only appeared 10 years ago. ${ }^{1}$ There are few reports in the literature of VATS sleeve resection for lung cancer ${ }^{2}$ performed with no direct visualization and no rib retractor. Other authors have reported hybrid VATS sleeve resections, with direct visualization through the incision and the use of a soft tissue retractor. $^{3}$

Most of the authors describe the VATS approach to lobectomy via 3 to 4 incisions, but the surgery can be performed by only 1 incision with similar outcomes. ${ }^{4}$ Since June of 2010, we have used the uniportal approach as the elected technique for VATS lobectomy. As of January 2013, we have performed 170 uniportal VATS major pulmonary resections, including some advanced cases. Consequently, as we accumulated experience, we were able to perform surgery with VATS in more complex cases, thus expanding the indications for single-incision thoracoscopic lobectomy.
A critical technical issue is the management of the sutures to avoid tangling the ends of the untied ends. The management of the instruments and sutures is more crucial in VATS than in an open thoracotomy. Although the tension of the continuous membranous suture seems to be difficult to adjust with a VATS approach, the tension can be carefully adjusted with a sliding knot-pushing instrument. We prefer to tie the knots while placing the sutures to prevent them from becoming crossed.

Most surgeons protect the anastomosis with wellvascularized tissue to reinforce the bronchial suture line and prevent fistula or arterial injury, but there are no available randomized trials comparing wrapping with no wrapping techniques. Recent articles have reported the safety of sleeve anastomosis without coverage of tissue flap, even after neoadjuvant therapy. ${ }^{5}$

\section{References}

1. Santambrogio L, Cioffi U, De Simone M, Rosso L, Ferrero S, Giunta A. Video-assisted sleeve lobectomy for mucoepidermoid carcinoma of the left lower lobar bronchus: a case report. Chest. 2002;121:635-6.

2. Mahtabifard A, Fuller CB, McKenna RJ Jr. Video-assisted thoracic surgery sleeve lobectomy: a case series. Ann Thorac Surg. 2008;85:S729-32.

3. Nakanishi K. Video-assisted thoracic surgery lobectomy with bronchoplasty for lung cancer: initial experience and techniques. Ann Thorac Surg. 2007;84:191-5.

4. Gonzalez-Rivas D, Paradela M, Fieira E, Velasco C. Single-incision video-assisted thoracoscopic lobectomy: initial results. J Thorac Cardiovasc Surg. 2012;143:745-7.

5. Storelli E, Tutic M, Kestenholz P, Schneiter D, Opitz I, Hillinger S, et al. Sleeve resections with unprotected bronchial anastomoses are safe even after neoadjuvant therapy. Eur J Cardiothorac Surg. 2012;42:77-81. 